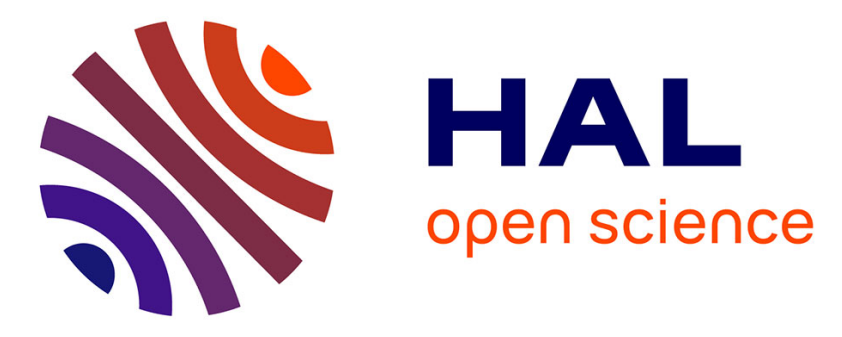

\title{
Morphological and chemical dynamics upon electrochemical cyclic sodiation of electrochromic tungsten oxide coatings extracted by in situ ellipsometry
}

Alexandre Zimmer, Mickaël Gilliot, Laurent Broch, Clotilde Boulanger, Nicolas Stein, David Horwat

\section{To cite this version:}

Alexandre Zimmer, Mickaël Gilliot, Laurent Broch, Clotilde Boulanger, Nicolas Stein, et al.. Morphological and chemical dynamics upon electrochemical cyclic sodiation of electrochromic tungsten oxide coatings extracted by in situ ellipsometry. Applied optics, 2020, 59 (12), pp.3766-3772. 10.1364/AO.389063 . hal-02558316

\section{HAL Id: hal-02558316 \\ https://hal.univ-lorraine.fr/hal-02558316}

Submitted on 12 Jul 2021

HAL is a multi-disciplinary open access archive for the deposit and dissemination of scientific research documents, whether they are published or not. The documents may come from teaching and research institutions in France or abroad, or from public or private research centers.
L'archive ouverte pluridisciplinaire HAL, est destinée au dépôt et à la diffusion de documents scientifiques de niveau recherche, publiés ou non, émanant des établissements d'enseignement et de recherche français ou étrangers, des laboratoires publics ou privés.

\section{(c)(1)}

Distributed under a Creative Commons Attribution| 4.0 International License 


\title{
Morphological and chemical dynamics upon electrochemical cyclic sodiation of electrochromic tungsten oxide coatings extracted by in situ ellipsometry
}

\author{
ALEXANDRE ZIMMER, ${ }^{1,2,{ }^{*}}$ MICKAËL GILLIOT, ${ }^{3}$ LAURENT BROCH, ${ }^{4}$ \\ CLOTILDE BOULANGER, ${ }^{2}$ NICOLAS STEIN, ${ }^{2}$ AND DAVID HORWAT ${ }^{5}$
}

\author{
${ }^{1}$ ICB, CNRS-Université de Bourgogne, 21078 Dijon, France \\ ${ }^{2}$ Université de Lorraine, CNRS, IJL, F-57000 Metz, France \\ ${ }^{3}$ LISM, Université de Reims Champagne-Ardenne, 51687 Reims, France \\ ${ }^{4}$ Université de Lorraine, LCP-A2MC, F-57000 Metz, France \\ ${ }^{5}$ Université de Lorraine, CNRS, IJL, F-54000 Nancy, France \\ *alex.zimmer@ellipsometrie.fr
}

Received XX Month XXXX; revised XX Month, XXXX; accepted XX Month XXXX; posted XX Month XXXX (Doc. ID XXXXX); published XX Month XXXX

The sodiation-desodiation process of sputtered amorphous electrochromic tungsten oxide coatings in aqueousbased medium was simultaneously monitored over 99 cycles by cyclic voltammetry and in situ spectroscopic ellipsometry. This allowed extracting the evolution of optical and geometrical parameters upon cycling. The resulting electrochemical coloring-bleaching process was dynamically fitted in the 1.8-2.8 eV optical range with a four-phase model including a constrained spline parametrization of the dielectric function. This allows real time access to thickness, surface roughness and dielectric function of $\mathrm{Na}_{\mathrm{x}} \mathrm{WO}_{3}$. The temporal evolution of the latter in the fully colored state was used to highlight a porosity extent of the probed coating of opened morphology. The designed spectro-electrochemical approach was applied to map the temporal evolution of the Na content $(x$ in $\mathrm{Na}_{x} \mathrm{WO}_{3}$ ) during and between cycles, taking into account the intricate interplay between charge density, thickness and electrolyte uptake. (C) 2020 Optical Society of America

\section{INTRODUCTION}

Among other chromogenics used for sustainable energy, amorphous tungsten oxide $\left(\mathrm{WO}_{3}\right)$ is an extensively studied cathodic electrochromic (EC) material allowing a control of its optical properties in the visible and NIR ranges in response to both external electrical charge and electrolyte's ions, $M$, insertion: [1-3]

$\left[\mathrm{WO}_{3}\right]_{\text {bleached state }}+\mathbf{x}\left(\mathrm{M}^{+}+\mathrm{xe} \mathbf{e}^{-}\right)=\left[\mathrm{M}_{\mathrm{x}} \mathrm{WO}_{3}\right]_{\text {bluish state }}$

Corresponding EC devices cover a widespread set of eco-efficient smart windows [4,5]. If intercalations of $\mathrm{Li}, \mathrm{K}$ or $\mathrm{H}$ ions are currently reported, they are not easily quantifiable $(\mathrm{Li}, \mathrm{H})$ and the case of hydrogen is also limited due to sensitivity to hygrometry. Moreover, $\mathrm{K}$ is seldom considered due to its poor ion conduction [6]. The intercalation of Na ions could then be alternatively considered despite its higher ionic radius, i.e. possible slower kinetics, compared to $\mathrm{H}$ and $\mathrm{Li}$. In addition, the rising field of sodium-ion batteries is calling for a greater attention to the $\mathrm{Nax}_{\mathrm{x}} \mathrm{WO}_{3}$ bronze system as a potential anode material [7]. Whatever the aforementioned applications, from the point of view of raw materials resources, solutions based on sodium appear more sustainable than those based on lithium [8].

Many studies focused on optical measurements and debated the coloration mechanism of sodium-tungsten bronzes. Thus, after pioneering works on optical properties [9], most reports on the dielectric functions were published in the 1970's and 1980's [10-15] whereas Tegg et al. computed it recently by means of DFT [16]. The deep blue cathodic coloration in such EC system [17] arises from the cumulative generation of electronic transitions between different $\mathrm{W}^{\mathrm{n}+}$ states, but based on different mechanisms in the amorphous or crystalline states [1] i.e. localization (e.g. small polarons) or electron delocalization (Drude behavior), respectively. We showed recently [18] that optical absorption in amorphous $\mathrm{Na}_{x} \mathrm{WO}_{3}$ follows the generalized site saturation model as it was shown for $\mathrm{Lix}_{\mathrm{x}} \mathrm{WO}_{3}$ [19] or $\mathrm{H}_{\mathrm{x}} \mathrm{WO}_{3}$ [20]. More particularly, we derived a unique optical model based on a constrained spline approach to draw out the pseudodielectric function spectra $(0.6-4.8 \mathrm{eV})$ whatever the state of the EC layer, i.e., as-deposited, colored ( $\mathrm{x}=0.1,0.2$ and 0.35$)$, and bleached $(\mathrm{x}=0)$ by 
means of ex situ spectroscopic ellipsometry (SE). This model allowed to assess the evolution of three polaronic transitions (ca. 1.3, 2.4, and $3.6 \mathrm{eV}$ ). Typically, all such EC systems reach a saturation level after the first coloring-bleaching cycles so that the amount of injected charges during coloring equals to that of extracted ones during bleaching. These preliminary cycles are considered as "activation" or "education" process $[6,17]$. The cationic intercalation is accompanied by a volume expansion of the oxide coating [5,18].

Another subject of interest is the reported degradation of EC performance of $\mathrm{WO}_{3}$ resulting from the electrochemical intercalation in aqueous medium [21,22]. Amorphous $\mathrm{WO}_{3}$ films dissolve in water to form tungstate-based ions which finally erode the films over several cycles i.e. a voltage-assisted dissolution [21]. The microstructure also plays an important role, the density of the films increasing their durability but increasing inversely their coloration and bleaching times [22]. Besides, if the phenomenon is slowed down in non-aqueous electrolyte thanks to both the poor ionizability and large size of organic molecules, together with the inhibition of tungstate ion release, this later can remain if the films are sufficiently hydrated $[21,23]$. Yet, data are still missing about the degradation for Na intercalation in aqueous medium. To the best of our knowledge, details on the evolution of the coating morphology during sodiation-desodiation cycle and throughout the whole electrochemical cycling are not available to date for this medium.

In this context, instead of transmission measurements[19,22,24] devoted to measure the optical modulation of coloring-bleaching process, optical methods based on reflective Spectroscopic Ellipsometry (SE) [25] are attractive alternatives as they bring more information about in situ processes, such as electrochemical ones occurring at the solid-liquid interfaces [26-28]. If significant researches have been conducted on $\mathrm{WO}_{3}$ and $\mathrm{M}_{\mathrm{x}} \mathrm{WO}_{3}$ systems by various groups, they essentially rely on ex situ monochromatic/spectroscopic or in situ monochromatic measurements [12,20,29-35]. Only a few ones have dealt with a full spectro-electrochemical approach [36,37]. For example, the open circuit dissolution of $\mathrm{WO}_{3}$ films was monitored by ellipsometry in aqueous solution, pointing out a zero-order rate law whatever the aqueous media tested. However this study, performed from monochromatic ellipsometry, has only considered thickness variations without any hydration and/or roughening process due to the inherent limitations of the method. Witham et al. [36] extracted the pseudo-dielectric function (at $400 \mathrm{~nm}$ ) during 3 cycles of hydrogenation-dehydrogenation process and modeled them using a Bruggeman effective medium approximation (BEMA) consisting of a mixture of fully colored and bleached states. They validated the model with the full spectral dependence $(310-830 \mathrm{~nm})$ during the coloration step. Camirand et al. obtained the $\mathrm{n}$ and $\mathrm{k}$ dispersion curves $(250-950 \mathrm{~nm})$ for $\mathrm{H}_{\mathrm{x}} \mathrm{WO}_{3} \quad(0<\mathrm{x}<0.32)$ during 36 cycles of chronoamperometric hydrogenation-dehydrogenation process [37]. The authors accessed some related coating properties in every bleached state during the cycling, like roughness evolution or thickness loss. For these reasons, we opted to transpose in situ our above-mentioned constrained splines based optical model, i.e. in a continuous way during each electrochemical cycle between colored and bleached states ( $\mathrm{x}$ between zero and maximum reachable values of $c a$. 0.35)

The purpose of this study is to investigate the ageing of $\mathrm{Na}_{\mathrm{x}} \mathrm{WO}_{3}$ during electrochemical cyclic sodiation in aqueous medium. In situ spectroscopic ellipsometry $(450-750 \mathrm{~nm})$ was used in order to follow the chemical evolution during 99 cycles of sodiation-desodiation process and to gain insights into its durability.

\section{METHODS}

\section{A. As-deposited samples}

As-deposited samples consist of $c a .2 .5 \times 2.5 \mathrm{~cm}^{2} \mathrm{WO}_{3}$ reactively sputtered films on ITO-coated glass substrates (typically $\sim 500 \mathrm{~nm}$ over 1 $\mathrm{mm}$ ). The morphology of coatings was additionally imaged with fieldemission scanning electron microscopy at $3 \mathrm{kV}$ (FEG SEM; Gemini SEM 500, ZEISS, Germany) before and after the protocol described in the following parts. Briefly, all of the as-deposited coatings were amorphous, substoichiometric (typically WO 2.7 but simply denoted as ' $\mathrm{WO}_{3}$ '). They possess an open morphology microstructure of columnar type suitable for electrochemical-intercalation of Na ions (Fig. 1a) thanks to a high working deposition pressure (4.5 Pa) [6]. The corresponding porosity $(\sim 30 \%)$ has been previously determined by experimental density $\left(\rho=4.72 \mathrm{~g} / \mathrm{cm}^{3}\right)[18]$. As aforementioned in the introduction, such morphology is known to accommodate a further volume change during the insertion-deinsertion of $\mathrm{Na}$ ions [5]. More details about the sputtering conditions can be found in [38].

\section{B. Electrochemical cycling conditions}

The control of the $\mathrm{Nax}_{\mathrm{x}} \mathrm{WO}_{3}$ optical properties is electrochemically performed via cyclic voltammetry (CV) using $0.1 \mathrm{M}$ solution of $\mathrm{Na}_{2} \mathrm{SO}_{4}$ buffered by a phthalate salt at $\sim 2.7 \mathrm{pH}$ unit $\left(0.1 \mathrm{M} \mathrm{C}_{8} \mathrm{H}_{5} \mathrm{KO}_{4} / 0.1 \mathrm{M} \mathrm{HCl}\right)$ as the electrolyte, saturated $\mathrm{Ag} / \mathrm{AgCl}$ electrode as a reference and Pt counter electrode. The sample, as working electrode, was embedded in a dedicated electrochemical cell (see next part). Figure $1 \mathrm{~b}$ illustrates the evolution of the cyclic voltammograms between the $1^{\text {st }}$ and the $99^{\text {th }}$ cycle. Each cycle consisted of a $25 \mathrm{mV} / \mathrm{s}$ cathodic scan from $+0.45 \mathrm{~V}$ to $-0.65 \mathrm{~V}$, and then anodically back to $+0.45 \mathrm{~V}$. A pronounced evolution of the film morphology was observed during the experiment. It is evident by comparing Figs. 1a and 1c. Details of this evolution will be discussed in the results section.
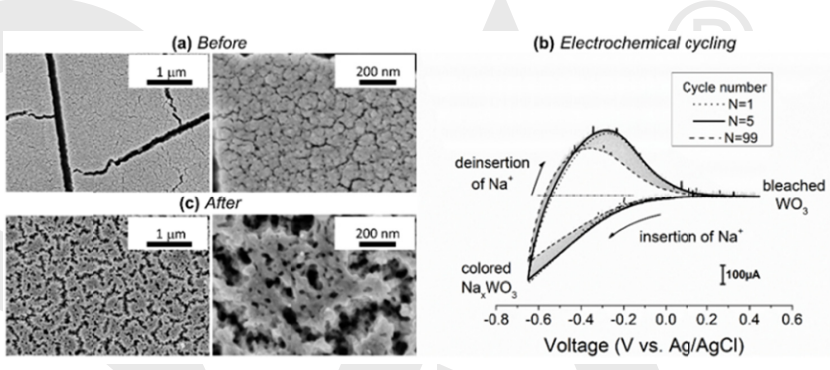

Fig. 1. (a) SEM plan view images for a representative sputtered amorphous $\mathrm{WO}_{3}$ coating on ITO coated glass substrate before electrochemical cycling (b) First; $5^{\text {th }}$ and $99^{\text {th }}$ cyclic voltammograms of coloring-bleaching in a $0.1 \mathrm{M} \mathrm{Na}_{2} \mathrm{SO}_{4}$ solution buffered by a phthalate salt at $\sim 2.7 \mathrm{pH}$ unit. Electrode area was $1.37 \mathrm{~cm}^{2}$, and scan rate was 25 $\mathrm{mV} / \mathrm{s}$ (c) Final SEM plan view images after electrochemical cycling.

\section{In situ ellipsometry}

\section{Setup}

Samples were analyzed in situ by spectroscopic ellipsometry (homemade setup [39]) during the aforementioned electrochemical cycling. Each sample was mounted as working electrode in a PolyEtherEtherKetone (PEEK) holder and placed vertically in a prototype coupling cell, which possesses two quartz windows allowing in and out polarized light beam. Prior to mounting each glass substrate back face was roughened in order to eliminate incoherent reflection. The incoming beam was emitted by a Xe-lamp ( $75 \mathrm{~W}$ ) and the outgoing beam is split into two perpendicularly-polarized waves and simultaneously analyzed by two synchronized CCD detectors, providing final spectrum of averaged ellipsometric angles $(\Psi(\lambda), \Delta(\lambda))$, free of systematic errors. The angle of incidence was precisely determined around $65^{\circ}$. The EC system was here investigated between the bleached state and the colored one in a typical limit of 129 collected ellipsometric spectra for each cycle (i.e. ca. 1.5 spectra per second) for limiting both raw data volume and calculation effort. For the same reasons, the fitting was performed on a selection of 11 cycles among the 99 available. Each cycle dataset was assigned to an integer, N, defined as the cycle number (Fig. 1b).

\section{Model and fitting procedure}


In order to determine the optical constants of $\mathrm{WO}_{3}$ dynamically during the sodiation-desodiation process, our previously mentioned model [18] is applied to kinetic SE data. Briefly, it consists of a four-phase structure i.e. electrolyte/surface rough layer/porous $\mathrm{WO}_{3}$ layer/ITO coated-glass substrate. The optical constants of the substrate were previously determined with no EC layer and electrolyte is assimilated to water [40] The top roughness was commonly treated as a BEMA of $50 \% \mathrm{WO}_{3}$ and $50 \%$ electrolyte [41]. For $\mathrm{WO}_{3}$, a first step consisted to extract its pseudodielectric function $\varepsilon(\lambda)$. Subsequently, in a post-fit step, this effective EC layer is accordingly treated as an another BEMA mixture in order to compute a relative porosity $\mathrm{f}$ by the following equation:

$\mathbf{0}=\mathbf{f} \frac{\varepsilon_{\mathrm{H} 2 \mathrm{O}}(\lambda)-\varepsilon(\lambda)}{\varepsilon_{\mathrm{H} 2 \mathrm{O}}(\lambda)+2 \varepsilon(\lambda)}+(\mathbf{1}-\mathbf{f}) \frac{\varepsilon_{\mathrm{ref}}(\lambda)-\varepsilon(\lambda)}{\varepsilon_{\mathrm{ref}}(\lambda)+2 \varepsilon(\lambda)}$

All the pores in $\mathrm{WO}_{3}$ are considered as fully filled by the electrolyte (dielectric function $\varepsilon_{\mathrm{H} 2 \mathrm{O}}$ ) with a f-electrolyte fraction and (1-f)-WO $\mathrm{W}_{3}$ fraction (dielectric function $\varepsilon_{\mathrm{ref}}$ ). $\varepsilon_{\mathrm{ref}}$ is relative to the reference $5^{\text {th }}$ cycle in the fully colored state of $\mathrm{WO}_{3}$, as explained in section 3.A.1.

The fitting method is based on a home build constrained spline algorithm, which is Kramers Kronig consistent and free of all a priori on the dispersion of the dielectric function [42]. Extracted film properties of interest consist of both optical (pseudo-dielectric function) and morphological parameters (thickness, roughness, relative porosity). The fitting accuracy was expressed by the mean square error (MSE) between experimental and generated $(\Psi(\lambda), \Delta(\lambda))$ values, and checked to avoid illconditioning.

\section{RESULTS AND DISCUSSION}

\section{A. Optical constants}

\section{Evolution during the initial reference cycle}

The coatings turned alternatively in a colored state (bluish coloration) after applying the cathodic scan and in a bleached one upon reversing the potential during the anodic scan (Fig. 1b). Varying the potential in such a manner allows accessing continuously, through the optical model, to the pseudo-complex refractive index $\tilde{\mathrm{n}}=\mathrm{n}+\mathrm{ik}$ or pseudo-dielectric function $\varepsilon=\varepsilon_{1}+i \varepsilon_{2}$ between the bleached and colored states. Figures $2 \mathrm{a}$ and $2 \mathrm{~b}$ show the limits of evolution of $\tilde{n}$ and corresponding $\varepsilon$ during the first fitted cycle dataset. This sodiation-desodiation cycle is the $5^{\text {th }}$ and is considered as the reference i.e. it is assumed that the oxide coating is conveniently activated and that degradation is neglecting. The corresponding full temporal evolution of $\varepsilon_{2}$ is also given in Video Clip 1 (see Visualization 1). After applying potential from $0.45 \mathrm{~V}$ to $-0.65 \mathrm{~V}, \mathrm{n}$ values decrease while $\mathrm{k}$ values increase at the same time in the covered part of visible spectrum. These trends are similar to those reported for $\mathrm{H}_{\mathrm{x}} \mathrm{WO}_{3}$ bronzes [34,37]. Moreover pseudo-dielectric functions of $\mathrm{NaxWO}_{3}$ previously obtained ex situ under quite similar experimental conditions [18] are superimposed in Figure 2b for extended spectral range. One reasonably argue that in situ-determined $\varepsilon_{2}$ (Fig. 2b, gray line) can be qualitatively ascribed as a portion of the reported asymmetric polaronic absorption curve (Fig. 2b, black line). The latter is in fact the superimposition of the three contributions already mentioned in the introduction.

\section{Evolution during consecutive electrochemical cycling}

If the above-described behavior of the pseudo-optical constants remains the same after the initial reference cycle, the fully colored state becomes more and more deprecated from the $10^{\text {th }}$ cycle, as depicted in terms of $n$ and $\mathrm{k}$ in Fig. 2c and Fig. 2d. Indeed, inserts of Figures $2 \mathrm{c}$ and 2d show, at 633 $\mathrm{nm}$, that $\mathrm{n}$ decreases from 1.7 to 1.5 while $\mathrm{k}$ decreases from 0.28 to 0.11 , corresponding to nearly linear degradation rates of $2.1 \times 10^{-3}$ per cycle and $1.7 \times 10^{-3}$ per cycle, namely $12 \%$ and $39 \%$, respectively. The cause of such degradation can be found in the evolution of the coating morphology as emphasized hereinafter.
Figure 1c displays additional SEM surface pictures at the end of the electrochemical cycling, revealing a drastic extent of the coating's nanoporous network. This feature is found similar to aged $\mathrm{WO}_{3}$ sol-gel coatings presenting an increase of channels crack size, suggesting a strong corrosion of the oxide network [23]. An excessive porosity level was also suggested by others to explain the degradation in long term durability of $\mathrm{WO}_{3}$ coatings [22]. Such hypothesis was then tested to explain the evolution of pseudo-optical constants depicted in Figs. 2c-d, using Eq.(2) and plotted in Fig.3. After the $10^{\text {th }}$ cycle, the electrolyte content already exceeds $3.8 \%$ and further increases up to $\sim 50 \%$ plateau above the $90^{\text {th }}$ cycle. Such extent of electrolyte penetration (swelling-like process [23]) is in qualitative agreement with the SEM plan views taken after the 99th cycle (Figs. 1a and $1 c)$, as claimed $[22,43]$.

To further validate the extracted dispersion curves, the coloration efficiency (CE) has been estimated as proposed by others [35,37]. This EC figure of merit represents the change in optical density (OD) per amount of charge density inserted $\left(\left|q_{c}\right|\right)$ or deinserted $\left(q_{a}\right)$ through the coating (Fig. 4, left axis). OD were here reversely simulated from the ellipsometric data for the selected cycles of Fig. 3. CE values at $650 \mathrm{~nm}$ upon cycling (Fig.4, right axis) are in good accordance with the tabulated value for analogous insertion in $0.1 \mathrm{M} \mathrm{Na}_{2} \mathrm{SO}_{4}$ electrolyte $\left(\mathrm{ca} .15 \mathrm{~cm}^{2} . \mathrm{C}^{-1}\right)$ [44].
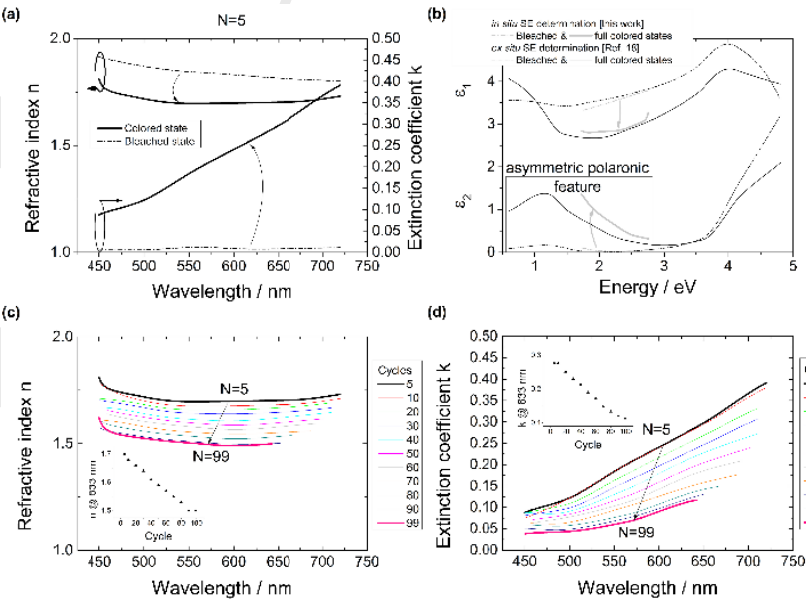

(d)

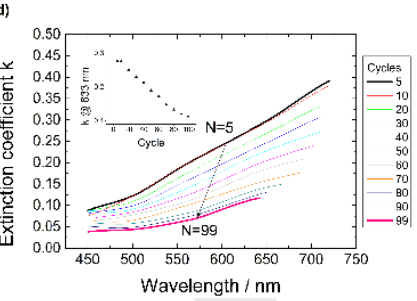

Fig.2 Best-fitted (a) pseudo-complex refractive index limits and (b) pseudo-dielectric function limits during the $5^{\text {th }}$ cycle of sodiationdesodiation for a representative sputtered amorphous $\mathrm{WO}_{3}$ coating. (c, d) Best-fitted pseudo-optical constants evolution associated with the fully colored state during electrochemical cycling. Inserts display the respective evolution of each optical constant at $633 \mathrm{~nm}$. Additional Video Clips of $\varepsilon_{2}$ during each mentioned cycle are available as supplementary material (see Visualization 1 for $\mathrm{N}=5$, Visualization 2 for $\mathrm{N}=10$, Visualization 3 for $\mathrm{N}=20$, Visualization 4 for $\mathrm{N}=30$, Visualization 5 for $\mathrm{N}=40$, Visualization 6 for $\mathrm{N}=50$, Visualization 7 for $\mathrm{N}=60$, Visualization 8 for $\mathrm{N}=70$, Visualization 9 for $\mathrm{N}=80$, Visualization 10 for $\mathrm{N}=90$, and Visualization 11 for $\mathrm{N}=99$ ).

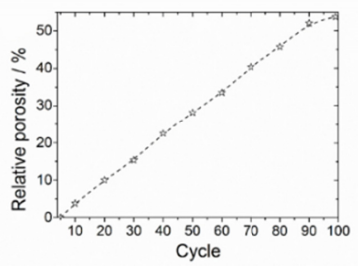

Fig. 3. Calculated porosity extent during the electrochemical cycling of $\mathrm{Na}_{x} \mathrm{WO}_{3}$ relatively to the reference $5^{\text {th }}$ cycle. The dashed line is a guide to the eye. 


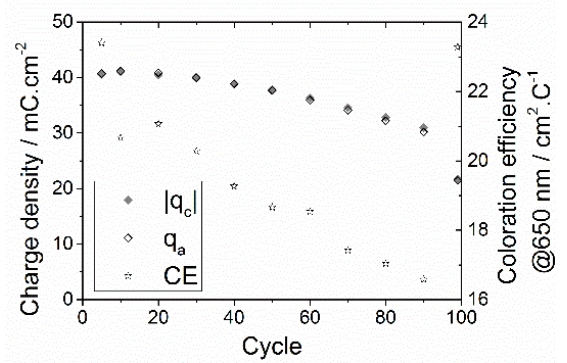

Fig. 4. (Left axis) Inserted $\left(\left|q_{c}\right|\right)$ and extracted $\left(q_{a}\right)$ charge densities and (Right axis) Coloration efficiency (CE) calculated at $650 \mathrm{~nm}$ for a representative sputtered amorphous $\mathrm{WO}_{3}$ coating on ITO coated glass substrate, during the electrochemical cycling in a $0.1 \mathrm{M} \mathrm{Na}_{2} \mathrm{SO}_{4}$ solution buffered by a phthalate salt at $\sim 2.7 \mathrm{pH}$ unit.
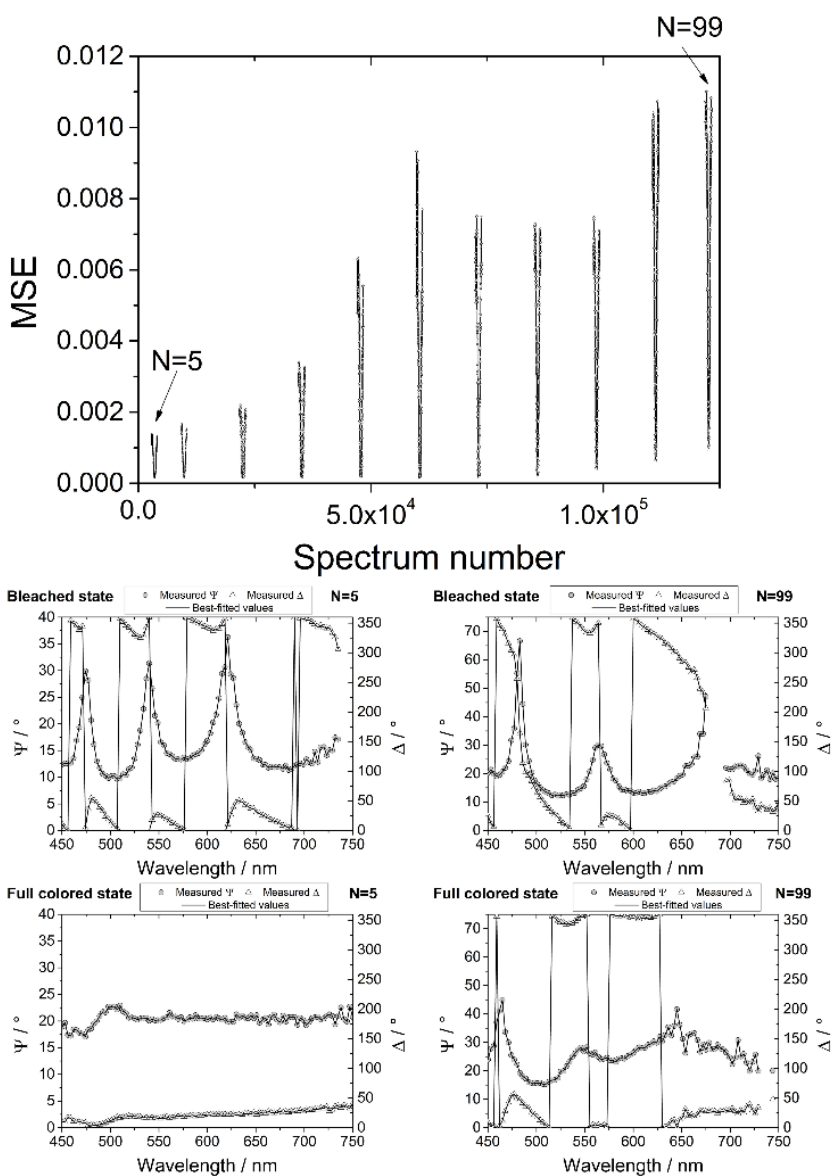

Fig. 5. (Top) Best-fitted mean square error (MSE) values during a whole sodiation-desodiation sequence for a representative sputtered amorphous $\mathrm{WO}_{3}$ coating. To minimize the calculation effort only 11 cycle datasets on 99 available cycle datasets are fitted (each cycle dataset consists of $c a .129$ spectra) (Bottom) Representative measured and best-fitted $(\Psi, \Delta)$ spectra for $\mathrm{N}=5$ and $\mathrm{N}=99$.

\section{Fit quality}

The top panel of Fig. 5 presents MSE values obtained during the whole sodiation-desodiation process. For the sake of brevity, only some cycles between the $5^{\text {th }}$ and the $9^{\text {th }}$ cycle are represented. For each the of the 11 cycle datasets, it is noticeable that a clear MSE minimum value exists and which strictly coincides to the maximum sodiation when correlated with corresponding electrochemical datasets, i.e. with the fully colored state. In contrast MSE maxima coincide with the bleached state. The overall MSE level ( $c a . \leq 0.01$ up to $\mathrm{N}=99$ ) indicate that the output parameters can be considered with good confidence, i.e. the quality of the fit further supports the validity of the model. The bottom panel of Fig.5 displays some illustrative matches between measured and best-fitted spectra. However, the model better applies in the insertion state than in the deinsertion one. The relative drift of the MSE values from $\mathrm{N}=5$ to $\mathrm{N}=99$ is undoubtedly a sign of the ongoing deterioration of the coating as it has been explained above in Section 3.A.2, but with some 'optical healing' effect at the fully colored states (min. MSE $c a . \leq 0.001$ up to $\mathrm{N}=99$ ).

In addition, some misfits usually occur in more or less quantity due to the inherent quality of kinetic spectra that imply e.g. to reduce the fitted spectral range to get optical parameters, as shown in Fig. $2 \mathrm{c}$ and Fig. 2d. Yet, the general evolution remains valid.

\section{B. Coulometric and geometrical factors}

\section{Charge density}

After the first initial 5 cycles, the excessive porosity revealed by Fig. 3 impairs the sodiation-desodiation process in such a way that $\left|\mathrm{q}_{\mathrm{c}}\right| \simeq \mathrm{q}_{\mathrm{a}}$ and $\mathrm{CE}$ values decrease with electrochemical cycling (Fig. 4). It is possible to get deeper in this analysis taking into account not only the charge during each cycle but also a full geometrical picture i.e. the available volume, in terms of porosity and both expansion and erosion-loss effects through thickness, to estimate the evolution of the Na content $\mathrm{x}$ in the tungsten bronze. This can be derived thanks to the dynamic properties determined by in situ SE.

\section{Thickness and roughness}

Based on observations of the film morphology before and after experiments (see Fig. 1) and knowing the dynamics of the electrical parameters, it is possible to derive a complete picture of the temporal evolution of both film geometry and composition.

Typical dynamics of the geometrical parameters are presented in Figure $6 \mathrm{a}$ for the reference cycle (i.e. the $5^{\text {th }}$ ). First of all, the thickness dynamics reveals the oxide expansion [38] upon Sodium insertion distinguishable from 0 to $\sim 35 \mathrm{~s}$, followed by the oxide contraction upon Sodium removal with another threshold from $\sim 60 \mathrm{~s}$ to $88 \mathrm{~s}$ (Fig. 6a, filled symbols). In between, a mean level around $534 \mathrm{~nm}$ at $48 \mathrm{~s}$ can be estimated including the maximum Sodium insertion of this initial cycle (arrow on the axis of Fig. 6a). This thickness evolution obtained here in situ is consistent with previous ex situ one [18]. The roughness is also found to evolve in such a manner, the colored state being slightly rougher than the bleached one (Fig. 6a, half-filled symbols).

The morphological evolution during the 99 cycles is summarized in Figure $6 \mathrm{~b}$. The following quantities are calculated

$$
\begin{aligned}
& d_{E X P .}=\frac{\overline{d(C S, N)}-\overline{d(B S, N)}}{\overline{d(B S, N)}}(\%)(3) \\
& r m s_{E X P}=\frac{\overline{r m s(B S, N)}-\overline{r m s(B S, 5)}}{\overline{r m s(B S, 5)}}(\%)(4)
\end{aligned}
$$

where $d_{E X P}$. and rmsEXP. are the thickness expansion during a single cycle and the roughness expansion with respect to cycle $\mathrm{N}=5$, respectively. $\overline{d(i, N)}$ and $\overline{r m s(j, N)}$ are the mean values of the fitted thickness and roughness during the EC state i or j (maximum colored state quoted ' $\mathrm{CS}$ ', or bleached state quoted 'BS') of the $\mathrm{N}^{\text {th }}$ cycle, respectively (see for example Fig. 6a, dashed lines, for $\overline{d(C S, 5)}$ and $\overline{d(B S, 5)}$ ).

First, the volume expansion trend is progressively strengthening up to a $\mathrm{d}_{\mathrm{EXP}}$. value of $c a .14 \%$. Concerning the temporal evolution in the bleached state (not shown) it appears weak and too scarce to be considered as a marked effect. Secondly, the roughness also varies: the rms values in the 
colored state are found slightly superior to these in the bleached state, whatever the cycle considered. Some analogous results using Chronoamperometric (CA) cycles in the case of $\mathrm{H}_{\mathrm{x}} \mathrm{WO}_{3}$ in more severe electrolyte [37], but in the sole bleached state, reveal the following evolutions: roughness increases from 3 to 7 times after 36 CA cycles relative to as-deposited $\mathrm{WO}_{3}$ and thickness losses of $\sim 2-10 \%$ in the same time. In our case, there is no significant evolution of the thickness and roughness of the bleached between cycles. In conclusion, our chemical conditions are less acidic (2.7 instead of 1 ), and the potentiodynamic of CV leads to progressive cations insertion by comparison with fixed applied potential (CA).

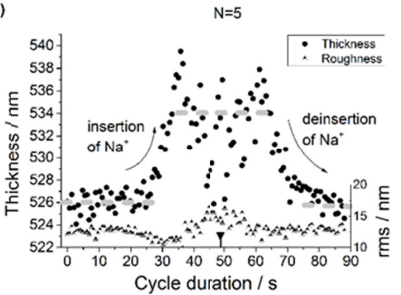

(b)

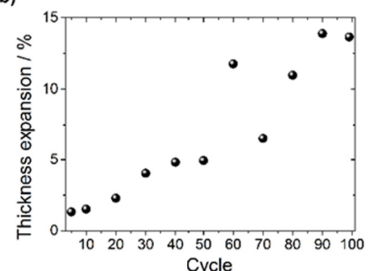

Fig. 6 (a) Best-fitted morphological parameters during the $5^{\text {th }}$ cycle of sodiation-desodiation for a representative sputtered amorphous $\mathrm{WO}_{3}$ coating. Arrow indicates the threshold of insertion-deinsertion of Sodium ions according Fig.1. The dashed lines are the mean values for the thickness in both limit EC states (b) Evolution of dEXP. during the electrochemical cycling.

\section{Mapping of $x$}

Finally, it is possible to derive a chemical information during the bronze degradation by estimating the evolution of the Na content, $\mathrm{x}$ (or $\Delta \mathrm{x}$ ), through each fitted cycle datasets by applying usual assumptions [18]

$x=\frac{n(N a)}{n(N a)+n\left(W O_{3}\right)}(5)$

where $n(\mathrm{Na})$ is the molar quantity of Sodium and $n\left(\mathrm{WO}_{3}\right)$ this of tungsten oxide. The first quantity is calculated using electrochemical data

$n(N a)=q_{c}(t) / F(6)$

where $\mathrm{q}_{\mathrm{c}}(\mathrm{t})$ is equal to the charge integration during insertion (Fig. 5) and $F$ the Faraday constant. The second quantity is estimated as follows

For the initial reference cycle i.e. $\mathrm{N}=5$ : (reference for the further porosity extent)

$n\left(W O_{3}\right)=S_{a} \times d(t) \times \rho / M(7)$

For the cycles $\mathrm{N} / 5<\mathrm{N} \leq 99$;

$n\left(W O_{3}\right)=S_{a} \times d(t) \times(100-\mathbf{f}) \times \rho / M(8)$

where $S_{a}$ is the active electrode area $\left(1.37 \mathrm{~cm}^{2}\right), \rho$ the $W_{3}$ density (see Section 2.A), M its molar mass $(231.84 \mathrm{~g} / \mathrm{mol}), \mathrm{f}$ the porosity fraction determined for each cycle (Fig. 4) and $\mathrm{d}(\mathrm{t}$ ) the thickness at each fitted time spectrum during the $\mathrm{N}^{\text {th }}$ cycle.

It is possible to map the evolution of $\mathrm{x}$ taking into account both volume expansion and loss (via $d$ by ellipsometry) and the injected charge (via $q$ by CV) during the whole electrochemical sequence. For a given cycle, the evolution of $\mathrm{x}$ vs time is a Gaussian-like curve (see insert of Fig. 7 for reference cycle $\mathrm{N}=5$ ). The calculated dynamics during each cycle and with cycle number of $\mathrm{x}$ in $\mathrm{Na}_{\mathrm{x}} \mathrm{WO}_{3}$ bronze coatings versus cycle duration and cycle is shown in Fig. 7. $x$ shows a peak value slightly increasing up to the $90^{\text {th }}$ cycle concomitantly as the pseudo-optical constants of $\mathrm{Na}_{x} \mathrm{WO}_{3}$ lower as more porosity occurs. Data of Fig. 6 evidence a change in film geometry upon sodium incorporation, in line with expansion of the molar volume already reported [4]. Moreover, increasing the number of cycles leads to progressive increase of the film porosity, leaving some free space for the molar volume expansion. Therefore, the maximal value of $\mathrm{x}$ reachable during insertion is expected to increase with the number of cycles, as observed with our calculated values reported in Fig 7.

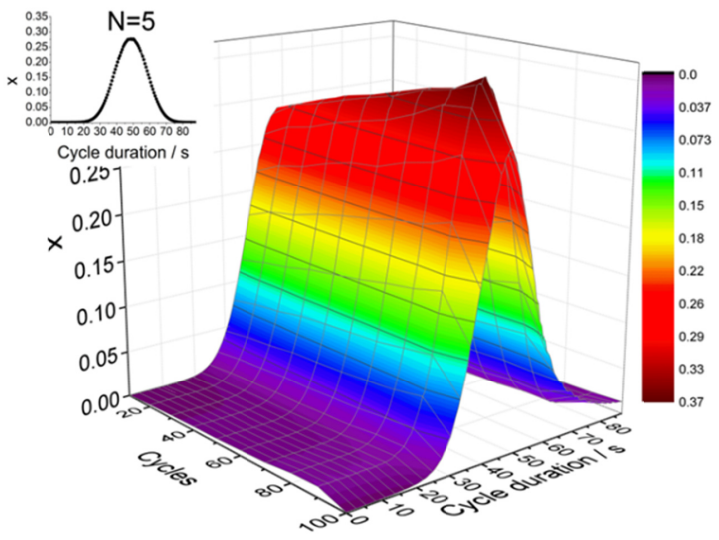

Fig. 7. Spectro-electrochemical determination of the Sodium content (x) evolution in $\mathrm{Na}_{\mathrm{x}} \mathrm{WO}_{3}$ bronze coating, as function of electrochemical cycling. Insert: activated cycle $(\mathrm{N}=5)$

In summary, the in situ spectro-electrochemical strategy developed enables deriving relevant information on both morphological and composition evolutions upon electrochemical cycling. It is found that as part of the tungsten oxide film is dissolved, it gains more ability to accommodate volume expansion during the cathodic phase and more sodium-ions can be incorporated per unit volume of the electrochromic film. This is in line with the fact that as-deposited films of opened morphology can more efficiently intercalate sodium ions than dense films $[6,22]$.

\section{CONCLUSION}

In situ spectroscopic ellipsometry study was performed on half electrochromic cell operating in aqueous electrolyte. The voltage-driven sodiation-desodiation process of sub-stoichiometric sputtered amorphous tungsten oxide coatings was monitored to focus on the electrochemical cycling observed over 99 redox switches i.e. electro-coloring followed by electro-bleaching. Using a unique constrained spline parametrized model, both optical and morphological parameters were successfully fitted.

Analysis of the sodiation-desodiation process reveals a degradation after the first activation cycles. By considering the calculation of a coating porosity extent, the pseudo-dielectric functions are found in accordance with a progressive incorporation of more than half additional electrolyte content than in the initial cycles. This appears as the main reason for the pseudo-optical properties attenuation with time, whereas the corrected available volume for injection also provokes the sodium content to slightly increase.

Acknowledgment. Authors acknowledge Sandrine Mathieu (IJL) for SEM observations and José Lopez (Université de Lorraine) for the fabrication of the coupling cell. Ellipsometric data were acquired at the Ellipsometry core facility of LCP-A2MC (Université de Lorraine - http://lcp-a2mc.univlorraine.fr).

\section{Disclosures}

The authors declare no conflicts of interest.

\section{References}

1. C. G. Granqvist, Handbook of Inorganic Electrochromic Materials (Elsevier, 1995).

2. L. Beluze, M. Morcrette, B. Viana, J. C. Badot, N. Baffier, and J. M. 
Tarascon, "Infrared electroactive materials and devices," Journal of Physics and Chemistry of Solids 67, 1330-1333 (2006).

3. G. Cai, P. Darmawan, X. Cheng, and P. S. Lee, "Inkjet Printed Large Area Multifunctional Smart Windows," Adv. Energy Mater. 7, 1602598 (2017).

4. C. G. Granqvist, "Fenestration for reducing building cooling needs," in Eco-Efficient Materials for Mitigating Building Cooling Needs (Elsevier, 2015), pp. 441-471.

5. P. R. Somani and S. Radhakrishnan, "Electrochromic materials and devices: present and future," Materials chemistry and physics 77, 117133 (2002).

6. D. Horwat, J. Pierson, and A. Billard, "Towards a thin films electrochromic device using NASICON electrolyte," Ionics 14, 227 233 (2008).

7. Z. Zhang, Y. Shao, B. Lotsch, Y.-S. Hu, H. Li, J. Janek, L. F. Nazar, C.-W. Nan, J. Maier, M. Armand, and L. Chen, "New horizons for inorganic solid state ion conductors," Energy \& Environmental Science 11, 1945-1976 (2018).

8. M. D. Slater, D. Kim, E. Lee, and C. S. Johnson, "Sodium-ion batteries," Advanced Functional Materials 23, 947-958 (2013).

9. B. Brown and E. Banks, "The sodium tungsten bronzes 1, 2," Journal of the American Chemical Society 76, 963-966 (1954).

10. F. Consadori and A. Stella, "Optical reflectivity of Na x WO 3," Lettere al Nuovo Cimento (1969-1970) 3, 600-603 (1970).

11. D. W. Lynch, R. Rosei, J. H. Weaver, and C. G. Olson, "The optical properties of some alkali metal tungsten bronzes from 0.1 to $38 \mathrm{eV}$," Journal of Solid State Chemistry 8, 242-252 (1973).

12. P. Camagni, A. Manara, G. Campagnoli, A. Gustinetti, and A. Stella "Optical properties of metallic sodium tungsten bronzes: Analysis of free- and bound-electron contributions," Physical Review B 15, 4623 4630 (1977)

13. J. F. Owen, K. Teegarden, and H. Shanks, "Optical properties of the sodium-tungsten bronzes and tungsten trioxide," Physical Review B 18, 3827 (1978)

14. K. Kang and M. Green, "Solid state electrochromic cells: optical properties of the sodium tungsten bronze system," Thin Solid Films 113, L29-L32 (1984).

15. M. Green and A. Travlos, "Sodium-tungsten bronze thin films: I. Optical properties of dilute bronzes," Philosophical Magazine B 51, 501-520 (1985)

16. L. Tegg, D. Cuskelly, and V. J. Keast, "The sodium tungsten bronzesas plasmonic materials: fabrication, calculation and characterization," Materials Research Express 4, 065703 (2017).

17. M. Kitao, S. Yamada, S. Yoshida, H. Akram, and K. Urabe, "Preparation conditions of sputtered electrochromic WO3 films and their infrared absorption spectra," Solar energy materials and solar cells 25, 241-255 (1992)

18. A. Zimmer, M. Gilliot, M. Tresse, L. Broch, K. E. Tillous, C. Boulanger, N. Stein, and D. Horwat, "Coloration mechanism of electrochromic NaxWO3 thin films," Opt. Lett. 44, 1104-1107 (2019).

19. L. Berggren and G. A. Niklasson, "Optical charge transfer absorption in lithium-intercalated tungsten oxide thin films," Applied physics letters 88, 081906 (2006).

20. Y. Yamada, K. Tajima, S. Bao, M. Okada, and K. Yoshimura, "Optical charge transfer absorption in proton injected tungsten oxide thin films analyzed with spectroscopic ellipsometry," Solid State Ionics 180, 659-661 (2009)

21. T. C. Arnoldussen, "A Model for Electrochromic Tungstic Oxide Microstructure and Degradation," J. Electrochem. Soc. 128, 117 (1981).

22. B. Baloukas, J.-M. Lamarre, and L. Martinu, "Electrochromic interference filters fabricated from dense and porous tungsten oxide films," Solar Energy Materials and Solar Cells 95, 807-815 (2011).

23. P. Judeinstein, R. Morineau, and J. Livage, "Electrochemical degradation of WO3 $\cdot$ nH2O thin films," Solid State Ionics 51, 239247 (1992).

24. E. Ozkan, S.-H. Lee, C. E. Tracy, J. R. Pitts, and S. K. Deb, "Comparison of electrochromic amorphous and crystalline tungsten oxide films," Solar energy materials and solar cells 79, 439-448 (2003).

25. R. Azzam and N. Bashara, Ellipsometry and Polarized Light (NorthHolland Publishing Company, 1977).
26. K. Hingerl, "Polarimetric and Other Optical Probes for the SolidLiquid Interface," in Ellipsometry at the Nanoscale, Springer (Losurdo, M., Hingerl, K., 2013), pp. 493-527.

27. A. Zimmer, L. Broch, C. Boulanger, and N. Stein, "Growth Mechanism during the Early Stages of electrodeposition of Bismuth telluride films," Electrochimica Acta 174, 376-383 (2015).

28. A. Zimmer, D. Veys-Renaux, L. Broch, N. Stein, and E. Rocca, "In situ spectroelectrochemical ellipsometry using super continuum white laser: Study of the anodization of magnesium alloy," J. Vac. Sci. Technol. B 37, 5 (2019).

29. D. J. Beckstead, "An Optical Study of Hydrogen Insertion in the Anodic Oxide of Tungsten," J. Electrochem. Soc. 136, 362 (1989).

30. E. Masetti, S. E. Segre, and S. Bosch, "Development of a phasesensitive ellipsometer and application to the real-time analysis of chromogenic WO3 films during the coloration process," Thin Solid Films 313-314, 62-67 (1998).

31. M. Saenger, T. Höing, B. W. Robertson, R. Billa, T. Hofmann, E. Schubert, and M. Schubert, "Polaron and phonon properties in proton intercalated amorphous tungsten oxide thin films," Physical Review B 78, 245205 (2008)

32. I. Valyukh, S. Green, H. Arwin, G. A. Niklasson, E. Wäckelgård, and C. G. Granqvist, "Spectroscopic ellipsometry characterization of electrochromic tungsten oxide and nickel oxide thin films made by sputter deposition," Solar Energy Materials and Solar Cells 94, 724732 (2010).

33. K. Adachi and T. Asahi, "Activation of plasmons and polarons in solar control cesium tungsten bronze and reduced tungsten oxide nanoparticles," Journal of Materials Research 1-6 (2012).

34. G. Yuan, C. Hua, L. Huang, C. Defranoux, P. Basa, Y. Liu, C. Song, and G. Han, "Optical characterization of the coloration process in electrochromic amorphous and crystalline WO3 films by spectroscopic ellipsometry," Applied Surface Science 421, 630-635 (2017).

35. Z. Hussain, "Optical constants and electrochromic characteristics of $\mathrm{M}_{\mathrm{x}} \mathrm{WO}_{3}$ bronzes," Appl. Opt. 57, 5720 (2018)

36. H. Witham, P. Chindaudom, I. An, R. Collins, R. Messier, and K. Vedam, "Effect of preparation conditions on the morphology and electrochromic properties of amorphous tungsten oxide films," Journal of Vacuum Science \& Technology A: Vacuum, Surfaces, and Films 11, 1881-1887 (1993)

37. H. Camirand, B. Baloukas, J. E. Klemberg-Sapieha, and L. Martinu, "In situ spectroscopic ellipsometry of electrochromic amorphous tungsten oxide films," Solar Energy Materials and Solar Cells 140, 77-85 (2015)

38. M. Tresse, "PhD. Thesis, Université de Lorraine, Nancy, France," (2016).

39. L. Broch, N. Stein, A. Zimmer, Y. Battie, and A. E. Naciri, "Design of a real-time spectroscopic rotating compensator ellipsometer without systematic errors," Thin Solid Films 571, 509-512 (2014).

40. M. R. Querry, D. M. Wieliczka, and D. J. Segelstein, "Water (H2O)," in Handbook of Optical Constants of Solids II, Academic Press (Palik, E.D., 1991), pp. 1059-1078.

41. V. D. Bruggeman, "Berechnung verschiedener physikalischer Konstanten von heterogenen Substanzen. I. Dielektrizitätskonstanten und Leitfähigkeiten der Mischkörper aus isotropen Substanzen," Annalen der physik 416, 636-664 (1935).

42. M. Gilliot, "Inversion of ellipsometry data using constrained spline analysis," Applied Optics 56, 1173-1182 (2017).

43. B. Reichmann and A. J. Bard, "The Electrochromic Processat W03 Electrodes Prepared by Vacuum Evaporation and Anodic Oxidation of W," Journal of The Electrochemical Society 126, 583-591 (1979).

44. K. J. Patel, C. J. Panchal, M. S. Desai, and P. K. Mehta, "An investigation of the insertion of the cations $\mathrm{H}+, \mathrm{Na}+, \mathrm{K}+$ on the electrochromic properties of the thermally evaporated WO3 thin films grown at different substrate temperatures," Materials Chemistry and Physics 124, 884-890 (2010) 